\title{
Report Card On E-Mail: An Investigation Of Replies To Consumers
}

Karen A. Berger (E-mail: Kberger@pace.edu), Pace University

Martin T. Topol (E-mail: Mtopol@pace.edu), Pace University

\begin{abstract}
Organizational communications have been studied from several vantage points, and typically as a one-way communication tool. Today, with the burgeoning growth and adoption of new technologies two-way communications have become ever more common. While this paper focuses its research attention to specific forms of e-mail communications between organizations and those it seeks as consumers, a conceptual framework is also presented that sets a foundation for examining and evaluating the myriad of communications alternatives that are available to organizations and the publics they serve.

In this exploratory study 165 companies were e-mailed each of two messages and their responses to these e-mails were analyzed. Firms used in the study were selected from seven different industries. The findings reveal that many firms have serious problems responding to fairly simple and common communications. Barely $45 \%$ of the firms studied responded to both types of inquiries, and many simply failed to respond. Further, there was considerable variability in the timeliness, clarity and specificity of response.

While one may assume that e-mail communication, as a technology is well understood given its proliferation, there are several factors that are discussed that may impede responsiveness - in timeliness, clarity or specificity. As a written form of communication, e-mail presents a challenge common to other forms of written communiqués; they provide a record that can be reviewed subsequent to the exchange between parties involved in communication. As such, organizations may be reluctant to answer all e-mails for a myriad of reasons: some may believe that e-mails place unnecessary or imposing demands on its workforce; some may fear that those responsible for handling the correspondence may be challenged to convey accurate, personalized information in an articulate manner; others simply do not want to have the burden of having to keep a record of such correspondence; yet others may simply view e-mail as a trivial or unimportant, irrespective of whether the communication was marked "urgent" or "confidential" by the sender; and others may fear that their e-mail correspondence is apt to become public, even if marked confidentialas email lacks the advantage of privacy that accompanied other more conventional written messages. Finally, hypotheses for future research based on the Customer Response System model are presented.
\end{abstract}

\section{Introduction}

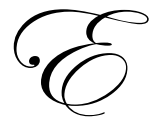

very facet of human life from friendship to business and government involves communication technologies. Increasingly, these days the communications form of choice is e-mail. In the corporate sector companies have discovered the two-edged sword of two-way communications: email can help create valuable relationships, but it can also undo relationships or destroy relationships that might have occurred. This paper briefly presents the results of a exploratory study on e-mail contents and e-mail response and then proposes a model of the process of the communication between customers and organization, hereafter called "A Customer Response System," based on the recognition that companies use a variety of communication media.

Readers with comments or questions are encouraged to contact the authors via email. 
Since the 1950s, companies have developed a correspondence with consumers. This form of correspondence traditionally took two weeks or more as companies received "snail mail" as it is now called and then answered the mail in the same slow way (Martin and Smart 1988, 1989, 1992). Problems with consumer correspondence have long existed, with research showing that complaining customers whose complaints are not answered are likely to remain dissatisfied (Bitner 1990).

In some industries companies developed call centers or hotlines that served to promptly respond to consumers. Martin and Smart (1994) report in their study of 109 firms that, overall, respondents were pleased with their 1-800 call experiences. With a cost of $\$ 1.20$ per call on average in 1994, Martin and Smart conclude that the cost of a call is far less than the cost of obtaining a new customer. However, with rising phone costs and service costs, companies have quickly looked to the Internet as an alternative.

With the emergence of the Internet, companies have invited consumers to correspond through the use of email forms, "contact-us" hotlinks and the like (Balabanis and Reynolds 2001). Unlike the other communications media, e-mail via a corporate Web site has created a flood-like response with the volume of e-mail nearly swamping corporate communications networks beyond imagination. Further, consumers have come to expect companies to respond with the information they want quickly. Consumers have taken to e-mail, because it provides simple, easy access to companies. In fact, it has been estimated that 96.6 million consumers have either a personal or business email address that they use (eMarketer 2000). One estimate has put the volume of e-mail messages in the United States for 2000 at 536 billion e-mail messages (Fischer 2001).

The ever increasing volume of e-mail has created a new set of problems. Instead of lowering costs, e-mail has now inundated firms with a growing variety of requests that place significant demands on those organizations committed to responding to consumer inquiries. Jupiter Communications, a leading e-commerce research firm, estimated that 65 percent of companies spend one percent to five percent of their total marketing budgets on e-mail marketing, and that an additional 22 percent of companies spend more than five percent (Fischer 2001).

Importantly, e-mail has begun to replace "older technologies," such as hotlines incorporating an "800" or toll-free number, voice mail messaging and "snail" mail correspondence. Ironically, this is not always by consumer choice! Increasingly, companies have constrained consumer access to them by NOT providing any alternative means of communication other than their Web site. Whether motivated by a desire to control costs or to control the organization's processing of customer communications, it seems clear that organizations need a better understanding of the impact of this new medium. For example, America Online no longer provides their telephone number to access its technical support staff. While AOL's decision was probably motivated by its concern for cost control, it may have been motivated by other concerns - such as ensuring that the most common inquiries are handled effectively and more thoroughly by the electronic media of its Website (e.g., posting of FAQs - Frequently Asked Questions and e-mail messaging).

The ascent of e-mail has been profound, for it is not simply a new method of communication overtaking older methods, it has become the mode of communication for both internal and external communications around the world. Undoubtedly, e-mail's relative cost advantage to the telephone and fax (e-mail is often viewed as "nearly free") weighs in along with other benefits obtained from the use of a digital medium that can be enhanced by those exchanging e-mail.

Given that effective handling of consumer correspondence is recognized as one way for businesses to maintain and enhance relationships with consumers (Martin and Smart 1989), the voluminous increase in correspondence via e-mail demands an examination of the organizational practices and processes of e-mail handling. Indeed, it has been suggested that optimization of an organization's e-mail communication process will enhance relationships and the flow of information between the organization and current and prospective customers.

From the point of view of the consumer, the need to address the demands of consumer communications has grown more critical as consumers have raised their expectations of what they want from companies. Consumers used to be satisfied with a response time by companies of seven days (Fenvessy 1970). Now the expectation is two 
days or less (Business Wire 2001). These types of changes make it all the more critical to understand the process of the flow of communication. The model presented here looks at this process and identifies several variables that affect the communications process that takes place (back and forth) between the organization and the consumer.

\section{Background of the Model}

The model presented here arose out of the need to explain the findings of an email response study developed by the authors. In this exploratory study one hundred sixty-five firms were e-mailed each of two messages respectively referred to here as E-mail 1 and E-mail 2. The firms' responses or lack of response were analyzed for each of the two e-mails. E-mail 1 (EM1) dealt with a request for catalog information and E-mail 2 (EM2) dealt with a request for security information (see Table 1). Firms used in the study were from seven different categories: brick and mortar retailers, leading e-commerce-only companies as identified by Business 2.0, communications firms on the Fortune 1000, financial institutions on the Fortune 500 list, food and drug manufacturers from the Fortune 500 list, computer and electronics e-commerce merchants, and finally, e-commerce travel firms drawn from the Gomez.com Certified computer e-commerce merchants list.

Table 1. Sample Content Of Email Messages Em1 And Em2

EM1

Please send me a hard copy of your most recent catalog and/or service

brochure to the following address:

P.O. Box

Goldens Bridge, NY 10526

Thank you in advance for your speedy reply.

EM2

I am thinking about placing an order on your Web site, but I am concerned about security. Please let me know the measures you have taken to secure your site and whether your site is Verisign or Trust-e approved.

Findings confirm that companies continue to have a problem with just answering their e-mail at all, much less on a timely basis. Only $45 \%$ and $42 \%$ of the companies receiving an e-mail actually answered EM1 and EM2, respectively. The balance of the companies, therefore, did not answer at all. Of the companies actually answering the e-mails, there were large variations in the response times. The average time of the response was 42 and 37 hours for EM1 and EM2, respectively. The standard deviations were 46 hours and 95 hours for EM1 and EM2, respectively.

There were wide variations in the content of the e-mails in this study as well in terms of use of personalization and how personalization was used, the solutions offered to customers, and the "customer friendliness" of Web sites. Personalization in the salutation and personalization in the signature were studied. This form of personalization is widely used in postal direct mail and was viewed as a first measure of personalization (Martin and Smart 1988; Smart and Martin 1992). In the authors' e-mail study, personalization in both the salutation and signature were below $60 \%$. 
As noted earlier, less than half the firms answered either of the e-mails. Of those answering the e-mails, $14 \%$ offered a full solution, $71 \%$ offered a partial solution and $14 \%$ did not offer any solution at all.

On the issue of ease of "correspondence" using e-mail, fourteen percent of the firms' Web sites required four or more clicks to get to a form or link. One can conclude that this number of clicks is not likely to be viewed as "customer-friendly" by many nor is it indicative of a desire to maintain open communication with consumers.

In viewing these findings, the authors have sought to organize their hypotheses using the model in Figure 1. The model proposed here is a general model for consumer response systems viewing e-mail as part of an entire program that companies have in place for communicating with consumers. The authors have taken a Customer Relationship Management [CRM] approach to model development. Since e-mail is a major way that consumers and companies communicate with each other, an approach which takes the premise that it costs less to keep the customer that you have than to try to win new ones is consistent with the fundamental principle of marketing or the marketing concept (Swift 2001).

\section{General Discussion of the Model}

The model presented in Figure 1 has five sequential decision making stages. The following scenario is assumed in a B2C context: the consumer provides companies with a variety of requests, compliments and complaints. Queries to the firm are received by the firm in three media forms: e-mail, telephone including voice or fax, and postal or 'snail' mail. At the first stage at the far left, goals of the organization and the communication determine the type of system, customer interface, and quality of service given to each query. Another way of saying this is that the organization sets up the systems that are made available for consumers to use. While consumers have some freedom to determine the means by which they communicate with a company, the company sets up the system for customer response. The three media in stage 2 each have their own modes of transmission and communication. Before communication can begin, the incoming message must move on to stage 3. In stage 3 , each message must be processed, routed and directed to the person or machine that will provide a response. Given the volume of mail that is received, it is likely that an organization must make decisions about how the tasks incorporated in stage 3 will be achieved. These days companies have discovered that they cannot handle e-mail without the help of technology. As such, companies like White Pyjama, Kana, RightNow Technologies and Boldfish have developed software and offer consultative services designed to help companies address the burgeoning demands of consumer communications. In stage four, the message character and content is determined or developed and sent on to the customer. Stage five recognizes that the message is likely to have a result. Basically, the consequences of the organization's reply will fall along a continuum which ranges from highly positive to highly negative outcomes - in other words, the firm's response can produce a significant benefit and/or competitive advantage or it can have a deleterious effect which may be temporary or permanent. Ultimately, the benefits to the firms that deploy e-mail as part of their communications media toolkit include immediate or short-term customer satisfaction, reduced costs of responding to the query of the customer, or the formation of a long-term customer relationship consistent with the benefits attributed to popular CRM applications.

Mediating the effects are the characteristics of the medium, characteristics of the message and the message content. Each of the media - e-mail, phone and snail mail - has characteristics that can affect the nature of the communication. These are referred to as characteristics of the medium. The message itself also has characteristics that are, to some degree, dependent upon the medium. Messages can also be effective or ineffective, efficient or inefficient, clear or unclear, or have a formal or informal form. They can also be ineffective, inefficient, unclear, or informal. The content of the message, specifically the language used and meaning conveyed, can also affect the nature of the communication. The message can be accurate or truthful in terms of the information provided in it; and it can provide a high concern for privacy, which may be especially valued by some consumers. These variables will be discussed later. Examples from actual corporate e-mails are shown in Table 1. 
Figure 1: Model of Customer Response System

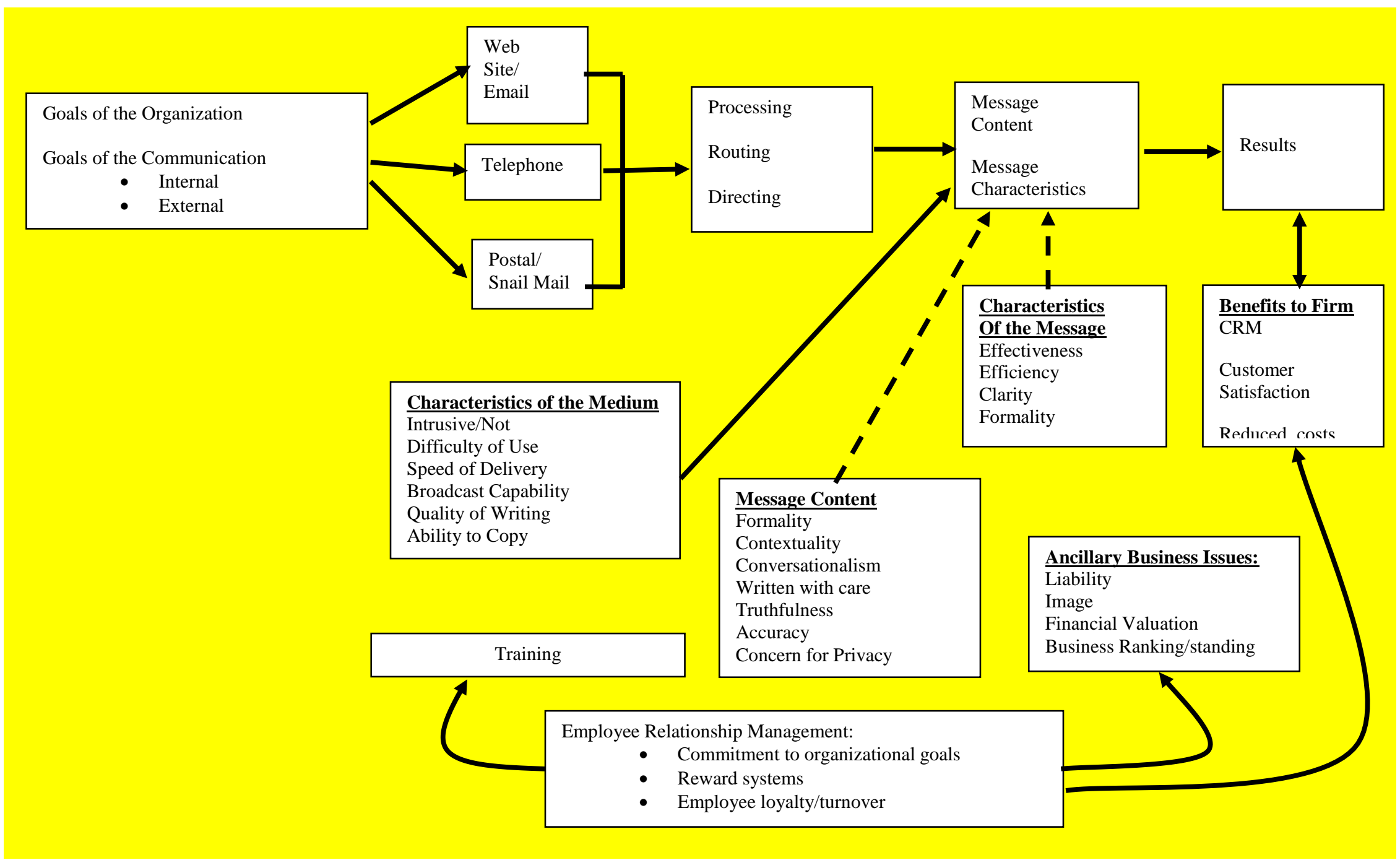




\section{Goals of the Organization and the Communication}

The Consumer Response System provided for consumers to correspond with companies about their needs, concerns and requests is dependent upon numerous factors. On a basic level, the response system that a company has is dependent on the extent to which the company has taken the time and allocated its resources (financial and human capital) to developing such a system. It seems fair to hypothesize that the more important customer service is perceived as important to the business, the more likely the system will encourage customer response and overall participation in a customer relationship. The development of a user-friendly, customer-oriented system is not to be assumed, as our exploratory research has found. Further, it is frequently reported by the press that companies have difficulties replying to email. For instance, Dodson (2000) references an Anderson Consulting study that reported that 42 percent of web merchants take four or more days to respond to customer e-mails. While this may win a race with other methods of response, it hardly appears to be up to Ainternet-speed.e

\section{Communication Medium: Characteristics of the Medium}

E-mail, telephone, fax and postal mail are four very different media. In fact, apart from the basic technological telecommunications underpinnings and infrastructure common to telephone, fax and e-mail required for of these media - the evolution of standardized equipment and interfaces were required before each of these media became significant to business-to-consumer correspondence. Building upon the concept of Marshall McLuhan (1967) that the "medium is the message", the notion that what is communicated can be different depending upon the medium used. The telephone, for example, can be very intrusive, especially if the call is an outbound call received by the consumer at the dinner hour or by a business customer during a hectic workday. The arrival of a fax or an express-mailed/couriered piece of 'snail' mail might herald a sense of urgency, but it may not be deemed intrusive. Email, by definition, is asynchronous allowing the sender to send at any time of day and the receiver to receive at any time of day. Each can choose when the message is sent or obtained, making the medium much less intrusive than the telephone.

Difficulty of use can vary for each of these media as well. For less proficient users of the Internet, finding the place on a Web site with an email address or "contact us" hotlink can be quite daunting. Sometimes the companies themselves "bury" the contact information and appear to purposely constrain consumer interaction and may cultivate a negative perception of the company's desire to be responsive. As noted earlier, the exploratory mailing of 165 firms resulted in $14 \%$ of the firms requested that a customer click four times to get to an e-mail form or address. Given the low click-through rates observed at numerous websites, a requirement of four or more clicks to reach an important customer service link seems to be counter-intuitive.

These media also vary according to speed of delivery with email being the fastest of the three. It is this dimension that has contributed greatly to the growth of e-mails. The ability of these media to reach large audiences at one time, or broadcast ability, varies as well with e-mail again surpassing the others. Conference calls limit the number of calls and regular faxes must be sent one at a time.

\section{Processing, Routing and Directing}

The way in which a message is processed, routed and directed can affect the speed by which a message is answered and the extent to which the message is answered. Call centers and e-mail management systems have become highly sophisticated; it is just a question of whether the firm can afford such a system and whether the company has identified the need. Mail systems, the postal variety, can be quite slow, although technology has reached this medium as well.

\section{The Message: Content and Characteristics}

Messages contain words that convey meaning. The meaning is conveyed by the way the words are put together in the message. The language in the message can convey many different meanings and messages. The language used in the message can be classified in a variety of ways: formality of language vs. contextuality, professio- 
nalism vs. conversationalism, written with care vs. not written with care, truthfulness vs. untruthfulness, accuracy vs. inaccuracy, and concern for privacy vs. the lack of concern for privacy, to name a few. This category of variables by which messages can be classified is called Message Content.

In the case of e-mail, the medium is not intrusive; the receiver of the message can obtain the message when it is convenient for him or her. On the other hand, the quality of the communication can be lost with e-mail, given the lack of voice elements, such as intonation, tone and accent. Comprehension can also be lost if the communication includes a string of e-mails back and forth, to and from the customer. In contrast, outbound telephone calls from the company can be quite intrusive, especially if the consumer is not ready for the call, or if the time of the call is deemed inappropriate or inconvenient by the recipient (consumer). While the quality of the message can be enhanced by the use of a live voice capable of deploying intonation, tone and accent to aid comprehension, enhance a sense of sincerity or other elements that may be interpreted as contributing to the "quality" of the communication, the fact remains that telephone communications are welcomed by consumers only if the customer is in a frame of mind to receive the message.

In contrast to most consumer correspondence sent by snail mail, e-mail can be very contextual and highly informal. This can help provide the consumer with the feeling that the company really cares or it can lead to the conclusion that the company is unprofessional (see Table 2 for examples).

These variables can be contrasted with variables that stem from the Characteristics of the Message. Since each message has a physical form, the physical form influences the way it is received and the consumer's ultimate response to the message. For example, snail mail in a consumer correspondence situation uses company stationery, is word-processed with an exacting format and may benefit from stylistic elements of fonts, tone, and personalization. In contrast, e-mail messages may not be received in the intended format - with its layout jagged, absent of personalization and rarely, if ever, signed by the sender. Admittedly, the layout/reformatting may be the result of the receiver's computer hardware or software; especially the receiver's Internet browser and e-mail application software, but this impacts the perceived character of the message.

In addition, e-mail responses are likely to be shorter than snail mail correspondence. While this brevity might not be intentional, it may be an artifact of the cultural expectations users may have for e-mail - keep the message simple and to the point.

Table 2: Message Variables

\begin{tabular}{|c|c|c|}
\hline Type of Variable & Variable Name & Example \\
\hline \multirow[t]{2}{*}{$\begin{array}{l}\text { Message } \\
\text { Content }\end{array}$} & $\begin{array}{l}\text { Formality/ } \\
\text { Contextuality }\end{array}$ & $\begin{array}{l}\text { Karen, service for what? } \\
\text { ConAgra Consumer Affairs } \\
\text { [All referents are missing from this email response; it is assumed that } \\
\text { the reader can supply the context]. }\end{array}$ \\
\hline & Truthful/Not truthful & $\begin{array}{l}\text { Thank you for your email. } \\
\text { At CircuitCity.com we are committed to providing excellent customer } \\
\text { service. One of our Customer Service Representatives will respond by } \\
\text { the end of the next business day. } \\
\text { Customer Support } \\
\text { Answer: (received } 48 \text { hours later) } \\
\text { Thank you for visiting CircuitCity.com. At this time, Circuit City does } \\
\text { not have a catalog available to send you. If you are interested in finding } \\
\text { out what specials Circuit City has at the present time, please visit } \\
\text { CircuitCity.com. Once you are on the CircuitCity.com home page, click } \\
\text { on "Specials" located toward the top of the page. } \\
\text { We also send out a weekly sales flyer in your local Sunday paper. } \\
\text { Thanks again for your inquiry. } \\
\text { Sincerely, } \\
\text { Chris Blanchard } \\
\text { Customer Support Coordinator } \\
\text { [This answer is truthful, because they delivered what they promised] }\end{array}$ \\
\hline
\end{tabular}




\begin{tabular}{|c|c|c|}
\hline \multicolumn{3}{|c|}{ Table 2: Message Variables (Continued) } \\
\hline $\begin{array}{l}\text { Message } \\
\text { Content }\end{array}$ & Accurate/Inaccurate & $\begin{array}{l}\text { I don't have brochures but would you accept a website?? Try } \\
\text { https://migrationsite.msn.com/qwest/default.asp?type=bb\& } \\
\text { This outlines our newest service with MSN. } \\
\text { [Web site does not show information about products/services] }\end{array}$ \\
\hline & $\begin{array}{l}\text { Concern for Privacy/ } \\
\text { No Concern for Privacy }\end{array}$ & $\begin{array}{l}\text { Yes, the web is secure. Check the key in the lower right hand corner. } \\
\text { [This terse email is accurate, but abrupt; no concern communicated in } \\
\text { the message] }\end{array}$ \\
\hline & $\begin{array}{l}\text { Concern for Privacy/ } \\
\text { No Concern for Privacy }\end{array}$ & $\begin{array}{l}\text { We know that your privacy on the Internet is very important to you. } \\
\text { That's why protecting your personal information is of the utmost impor- } \\
\text { tance to The Home Depot. } \\
\text { Shopping on homedepot.com is safe. When you place orders on home- } \\
\text { depot.com, all of your order information, including your card number } \\
\text { and delivery address, is passed through our server. Our secure server } \\
\text { uses Secure Sockets Layer (SSL), which encrypts your order informa- } \\
\text { tion and transmits it to us. SSL technology, the industry-leading stan- } \\
\text { dard, is designed prevent someone other than homedepot.com from } \\
\text { viewing and downloading your information. } \\
\text { While we're confident your order information is secure, if you feel at } \\
\text { all unsure about ordering online, please contact your local Home Depot } \\
\text { Store for information about placing your order in the store by phone or } \\
\text { fax. We can also take your gift card orders over the phone when you } \\
\text { call us toll free at 1-800-430-3376. } \\
\text { Thank you for contacting homedepot.com! } \\
\text { Sincerely, } \\
\text { Derek } \\
\text { homedepot.com }\end{array}$ \\
\hline & $\begin{array}{l}\text { Professional/ } \\
\text { Conversational }\end{array}$ & $\begin{array}{l}\text { Hello Karen, } \\
\text { We at websupport for the } \\
\text { American Express travel website do not have what you request. We } \\
\text { cannot assist you. } \\
\text { [Hello, Karen is conversational and personal in tone.] }\end{array}$ \\
\hline & $\begin{array}{l}\text { Written with Care/ } \\
\text { Not Written with Care }\end{array}$ & $\begin{array}{l}\text { Hi our site is ssl secured and we don't share any of our information's } \\
\text { with any one. We are using versign security for our site. } \\
\text { Aaron } Y \\
\text { [This message has punctuation and grammar errors] }\end{array}$ \\
\hline & $\begin{array}{l}\text { Clearly Written/ } \\
\text { Not Clearly Written }\end{array}$ & $\begin{array}{l}\text { Thank you for contacting VictoriasSecret.com! We're always happy to } \\
\text { hear from you and answer any questions you may have. We will re- } \\
\text { spond to your inquiry within the next } 24 \text { hours. Now you can check } \\
\text { your order status at any time on our website. Please 'copy and paste' the } \\
\text { URL into the address field of your brows- } \\
\text { er.http://www2.victoriassecret.com/orderstatus/Click "Go" and view } \\
\text { your information. Thank you for shopping with Victoria's Secret. } \\
\text { VictoriasSecret.com Client Services } \\
\text { http://www.VictoriasSecret.com }\end{array}$ \\
\hline & $\begin{array}{l}\text { Efficient - to the point/ Not } \\
\text { to the point }\end{array}$ & $\begin{array}{l}\text { Dear M.Topol, } \\
\text { Thank you for contacting Sears Online. } \\
\text { You can find out our privacy policy by going to www.Sears.com, click } \\
\text { on customer service icon, then scroll to privacy policy link. } \\
\text { If you have any comments or questions, please email us at } \\
\text { webcenter@ sears.com or call us at 1-800-349-4358. We hope you visit } \\
\text { us again soon at www.sears.com } \\
\text { Brandy } C \text {. } \\
\text { Sears Customer Care }\end{array}$ \\
\hline
\end{tabular}




\begin{tabular}{|c|c|c|}
\hline \multicolumn{3}{|c|}{ Table 2: Message Variables (continued) } \\
\hline $\begin{array}{l}\text { Message } \\
\text { Characteristics }\end{array}$ & $\begin{array}{l}\text { Formally Presented/ } \\
\text { Not Formally Presented }\end{array}$ & $\begin{array}{l}\text { Thank you. We have received your request for customer assistance with } \\
\text { your Dell product. We will respond to your communication as we reach } \\
\text { it in our incoming message queue. } \\
\text { We try to respond within } 24 \text { hours. } \\
\text { Our hours of operations are: } \\
\text { Mon-Fri } 7 \text { am }-9 \text { pm } \\
\text { Sat Sun } 9 \text { am-7 pm } \\
* * * * * * * * * \\
\text { Visit our Service and Support center at: } \\
\text { http://support.dell.com This site contains full specifications on all cur- } \\
\text { rent and past Dell systems. This is the exact same database that Dell } \\
\text { technicians use to answer your questions about your system. } \\
* * * * * * * * \\
\text { Thank you for your time and patience. Have a good day. } \\
\text { Respectfully, } \\
\text { Dina DTC16743 8AM-7PM CST Mon-Thurs } \\
\text { Dell Customer Care }\end{array}$ \\
\hline
\end{tabular}

\section{Ancillary Business Issues}

There are a number of potent business issues that arise with the introduction of e-mail. Focusing on business-to-consumer e-mail correspondence, companies are concerned about the legal ramifications of e-mails sent by any person it employs. The e-mail may contain an outright promise and commitment or simply be construed as such and, thereby creating, a liability for the firm. Contractual or not, such communications are a matter of record and have become pivotal in several legal battles involving a broad array of companies. What is said in response to the consumer's inquiry - the e-mail's content - and how it is said - the e-mail's character, language and tone - can bear dramatically on consumers' response to the communication and their perception of the sending organization and its representatives. As such, the image of the organization may be impacted by specific e-mails and the organization's e-mail messaging practices generally. Given the importance of image on consumer attitudes, image-impacting communications must be consistent with the broader communications goals (transactions, relationship building and branding) established by the organization (Albert and Sanders 2003).

\section{Training}

Corporate communications capabilities are largely the result of the resources deployed by the organization -- the persons it employs, the advertising, public relations and web-design agencies it hires to develop and place its communications, and the training that it provides to all of its employees. While it is likely that new hires are screened and selected based on their different skills and abilities, it is unclear as to whether companies have made any serious attempt to incorporate formal measures of written and oral communication skills in their recruiting programs. In this light, the importance of training becomes ever more important, particularly once the organization recognizes that the "results" - the Stage 5 outcomes of the Consumer Response Model presented here -- are influenced by the elements that comprise the inputs to and processes of the Model (Stages 1 through 4) and the employees that will have a hand in corresponding with the public via voice (telephone) or in writing (written communication of any kind including e-mail).

\section{Employee Relationship Management (ERM)}

An outgrowth of Customer Relationship Management (CRM), ERM has gained much recognition of late, with several industry conventions directed at training and development, software tools and other aides that are meant to address some of the human resource difficulties alluded to above. ERM advocates point to the intensified need to develop front-line customer-facing personnel with skills and abilities that enable them to respond to customer inqui- 
ries in an accurate, articulate and effective manner. Further, given today's tough and competitive environment, companies have to do all they can to be sure that they are keeping their business in the lead. Not surprisingly, several industry gurus and consultants advocate that employees must have the tools, training, information, and resources to effectively execute their organization's strategy. As such, communication skills - internal and external communications - are key to empowering the workforce and meeting organizational goals.

Frederick Reichheld (1996 and 2000) has long argued that loyalty is the hidden force behind organizational growth, profits and lasting value and has drawn on decades of experience to support this view. In fact, Reichheld demonstrates how employee loyalty bears directly upon customer loyalty and retention, which obviously impacts corporate profitability and long-run survival. Reichheld (1996, p. 4) states that companies must earn employee loyalty:

"People invest time and money loyally if they believe that their contributions to your company will yield superior returns over time. The secret is, therefore, to select these human beings carefully, then teach them how to contribute and receive value from your business system."

At the extreme employee loyalty results in zero defections and heightened stability of value-creating assets. As such, the long run benefits of selective hiring practices and a commitment to employee training and development are improved financial prospects and outcomes.

\section{Benefits to the Firm}

Effective communications and response systems are believed to be instrumental to customer satisfaction, customer retention, and in turn, reduced costs. Many have demonstrated the financial impact of loyalty and customer equity that can be derived from the most basic computations of the lifetime value of a customer. Hughes (2000), Best (2000) and Rust, Zeithaml and Lemmon (2001) demonstrate the long-run financial benefits associated with customer loyalty and retention. At a minimum, cost reduction is enjoyed by firms that have increased customer retention, since they are not forced to spend heavily on acquiring new customers to replace the customers they may have lost. The mantra of CRM is simple: customer acquisition is expensive and it is far less costly to keep a customer than to replace one. In fact, Hughes and Best pay particular attention to the value of customer referrals which in the context of this research may be enhanced by e-mails from customers to other prospective customers who they may know. Referrals are an efficient method of recruiting new customers - as it is the loyal, satisfied customer who recommends the company to others who are likely to be more inclined to establish a relationship with a company they now believe that they can trust.

The same can be said about employees. Once a company has earned the loyalty of its employees and a commitment to organizational goals, employee turnover is apt to decline. Further, these loyal employees can assist in recruitment efforts helping to select individuals they believe will share their commitment to the organization.

Reichheld (2001) states: "Loyalty is impossible without trust. Trust is impossible without accurate, reliable information." And he further admonishes: "Develop state of the art communication tools and listening skills so you and your partners can reach deeper levels of understanding that yield clearer priorities, coordinated actions, and superior results. Nothing magnifies the loyalty effect like the trust engendered by open, honest, and direct exchange of information and ideas.

\section{Future Research}

The model presented here identifies variables for study. The authors present here hypotheses for future study. 


\subsection{Goals of the organization:}

H1: The more important customer service is perceived as essential to the business, the more likely it will be to encourage efficient customer response and customer relationship management

\subsection{Communication Medium}

H2: The speed of the message will significantly affect the way the message is perceived by the consumer.

H3: The lack of intrusiveness of e-mail contributes to the view that e-mail is attractive as a means of consumer correspondence.

H4: Consumer attitude toward a company is directly related to the quality of writing in the e-mail they receive from the company (i.e., the better the quality, the more favorable the attitude is).

\subsection{Message Content}

H5: The perceived importance of an e-mail message is directly related to the perceived formality of the email message. (The more formal the message, the more important it is perceived to be).

H6: Because context is often not presented, there is a greater probability with e-mail that the intent of the message will be misunderstood (i.e., when the e-mail reply does not contain the original inquiry).

H7: If context is missing repeatedly in a message, the customer is more likely to feel s/he has not been sent the information requested.

\subsection{Characteristics of the Message}

H8: Snail mail messages written in a formal form are more likely to be perceived as more important than email messages in the same form.

\section{Conclusions}

There are many communications issues that need to be examined by researchers in order to better understand the impact of e-mail messages in consumer communication with organizations. The model presented here is a first look at how these issues may affect one another. This appears to be a potentially fertile research area.

\section{References}

1. $\quad$ Albert, Terri C. and William B. Sanders (2003), e-Business.Marketing, NJ: Prentice-Hall.

2. Balabanis, George and Nina L. Reynolds (2001), "Consumer Attitudes Towards Multi-Channel Retailers' Web Sties: The Role of Involvement, Brand Attitude, Internet Knowledge and Visit Duration”, Journal of Business Strategies, Vol. 1 (2), pp. $105-131$.

3. Best, Roger J., Market-Based Management: Strategies for Growing Customer Value and Profitability, (Second Edition), Prentice Hall, New Jersey, 2000.

4. Bitner, Mary Jo (1990), "Evaluating Service Encounters: The Effects of Physical Surroundings and Employee Responses", Journal of Marketing, Vol. 54 (April), 69-82.

5. Business Wire (2001), "Online Shopping Returns Survey Shows Some Improvement, But Overall Customer Care Still Lacking", February 20.

6. Dodson, Jody (2000), "It's Time To Chat With Your Customers". InternetWeek. September 18. http://www.internetweek.com/ebizapps/col091800.htm.

7. $\quad$ eMarketer, Inc. “ eMail Marketing Report”, 2000, pp. 65-66.

8. Fenvessy, Stanley J. (1970). "Customer Mail: How to Keep Friends”. Administrative Management. 31, Ju- 
ly, pp. 44-46.

9. Fischer, Edward (2001). Internet Special Report: “E-mail Done Right”. Target Marketing. August 1. North American Publishing Company.

10. Heylighen, Francis and Jean-Marc Dewaele (2001). "Variation in the Contextuality of Language: An Empirical Measure", working paper, Center "Leo Apostel", Free University of Brussels.

11. Hughes, Arthur M. (2000) Strategic Database Marketing, Second Edition, New York: McGraw-Hill.

12. Martin, Charles L. and Denise T. Smart (1988). "Relationship Correspondence: Similarities and Differences in Business Response to Complimentary Versus Complaining Consumers". Journal of Business Research, Vol. 17, Iss. 2, p. 155 - 173.

13. Martin, Charles L. and Denise T. Smart (1989). "Consumer Correspondence: An Exploratory Investigation of Consistency Between Business Policy and Practice”. The Journal of Consumer Affairs, Vol. 23, No. 2, pp. 364-382.

14. Martin, Charles L. (1994). "Consumer Experiences Calling Toll-Free Corporate Hotlines". Journal of Business Communication, vol. 31, 3, pp. $195-212$.

15. McLuhan, Marshall (1967). The Medium is the Message. Gingko Press, Inc.

16. Reichheld, Frederick F. (1996). The Loyalty Effect, Boston: Harvard Business School Press.

17. Reichheld, Frederick F. (2001). Loyalty Rules! How Today's Leaders Build Lasting Relationships, Boston: Harvard Business School Press.

18. Rust, Roland T., Valerie A. Zeithaml and Katherine N. Lemmon Driving Customer Equity: How Customer Lifetime Value is Reshaping Corporate Strategy, Free Press, New York 2000.

19. Smart, Denise T. and Charles L. Martin (1992). "Manufacturer Responsiveness to Consumer Correspondence; An Empirical Investigation Consumer of Perceptions". The Journal of Consumer Affairs, Summer.

20. Swift, Ronald (2001). Accelerating Customer Relationships. New York: Prentice-Hall.

Notes 